\title{
Model Predictive Current Control for High-Power Grid-Connected Converters with Output LCL Filter
}

\author{
Hernan Miranda, Remus Teodorescu \\ Department of Energy Technology \\ Aalborg University \\ Aalborg, Denmark \\ Email: hmd@iet.aau.dk
}

\author{
Pedro Rodriguez \\ Department of Electrical Engineering \\ Universitat Politecnica de Catalunya \\ Barcelona, Spain \\ Email: prodriguez@ee.upc.edu
}

\author{
Lars Helle \\ Vestas Wind Systems \\ Denmark \\ Email:LAH@vestas.com
}

\begin{abstract}
A model predictive control strategy for a highpower, grid connected 3-level neutral clamped point converter is presented. Power losses constraints set a limit on commutation losses so reduced switching frequency is required, thus producing low frequency current harmonics. To reduce these harmonics an LCL filter is used. The proposed control strategy allows control of the active and reactive power fed into the grid, reduce the switching frequency within acceptable operational margins and keep balance of the DC-link capacitor voltages while avoiding excitation of the filter resonance frequencies.
\end{abstract}

\section{INTRODUCTION}

Installation of wind power plants (WPP) have experienced a dramatic growth during the last years and it is expected that the total power installed will double in a few years [1]. Tied to this growth the power delivered by each wind turbine generator (WTG) has also increased. It is expected that connection with the grid through a full-scale converter will be the preferred technical solution since this allows decoupled control of active and reactive power (even during faults), and it is easier to control negative sequence components.

In order to keep power losses within acceptable margins, high-power converters (around $5 \mathrm{MW}$ ) present a critical limitation on the switching frequency. Available power semiconductors are usually limited to operate below $600 \mathrm{HZ}$. For a 3-level neutral point connected (NPC) converter this means that the switching frequency as seen in the line current is $1200 \mathrm{~Hz}$. Such low switching frequency will produce side bands harmonics that cannot be limited by a pure inductive line filter. In order to comply with harmonic injection standards, an inductive-capacitive-inductive (LCL) filter is preferred.

In recent years, some research has been developed in LCL filter design [2]-[5] and current control of LCL connected converters [2], [6] and [7]. In [2] and [6], linear controllers are used to damp the filter resonances, while in [7] state feedback is realized through a variable feedback gain, which is calculated depending on the state position within the state space plane, thus resulting in a piecewise linear controller. However, this solutions are all oriented to high frequency switching strategies (above $3 \mathrm{kHz}$ ).

The proposed strategy is based on model predictive control as presented in [8] and [9]. The strategy makes use of a discrete time model of the system to predict the future value of the control state for different control inputs. Each predicted state is introduced in a cost function containing the control objective, and the input producing the state with the lowest cost is applied during the following sampling instant. In this way, an on-line optimization control algorithm is obtained. This is particularly suitable for a 3-level NPC converter since it is possible to predict the system behavior for each of the 27 voltage vectors available.

The cost function to be optimized includes four different control objectives. The first one is fundamental current tracking in order to deliver the required active and reactive power into the grid. The second objective is to reduce the switching frequency to within the limits imposed by the power semiconductors (below $1200 \mathrm{~Hz}$ ). The third objective is to keep the DC-link capacitor voltages balanced, and the last control objective is to avoid excitation of the LCL filter resonance frequencies.

In section II the mathematical model required for each control objective is presented. The cost function associated to the control objectives is developed in section III. Active power control regulation is explained in section IV and simulations results for a $6 \mathrm{MW}, 3 \mathrm{kV}$ line voltage 3 -level NPC converter with $5 \mathrm{kV}$ DC-link voltage are presented.

\section{System Modeling}

The system under study is shown in fig. 1 and can be decomposed in five subsystems. Two of them: an external power source injecting active power, and the grid voltage $V_{g}$, can be considered as external disturbances since they can not be affected by internal variables and present a random behavior. The remaining three subsystems are: the DC-link filter with capacitances $C 1$ and $C 2$, an 3-level NPC converter and the LCL grid filter with converter side resistance and inductance $R_{1}$ and $L_{1}$, capacitor filter $C$ and grid side resistance and inductance $R_{2}$ and $L_{2}$. These subsystems are characterized by variables that must comply with certain performance indexes e.g. capacitor voltage balance (DC-link), switching frequency (power converter) or output harmonic content (LCL filter). In order to implement a control algorithm able to regulate these and other variables of interest a model of each of the system components must be developed. 


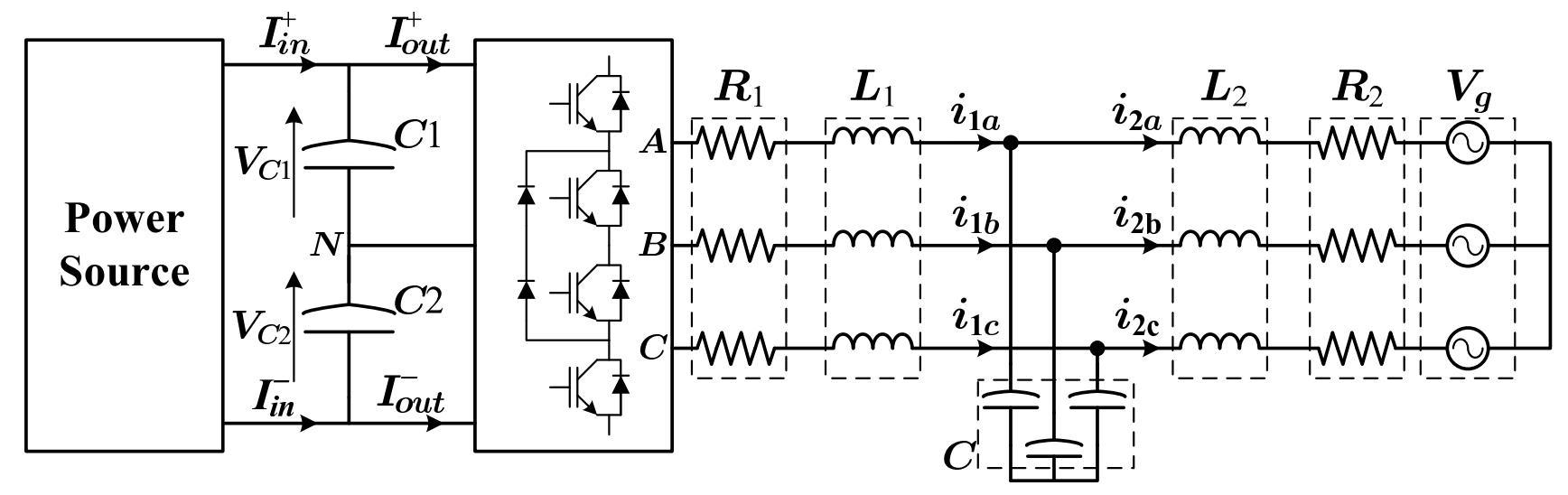

Figure 1. System configuration.

\section{A. DC-link model}

According to fig. 1 the currents flowing into the DC-link filter are $I_{i n}^{+}$and $I_{i n}^{-}$(superindex + for the positive bar, and - for the negative), and the currents going out of the DC-link are $I_{\text {out }}^{+}$and $I_{\text {out }}^{-}$. According to these definitions the capacitor voltages $V_{C 1}$ and $V_{C 2}$ are defined in discrete-time as in (1) and (2).

$$
\begin{aligned}
& V_{C 1}[\mathrm{k}+1]=V_{C 1}[\mathrm{k}]+\frac{\Delta t}{C 1}\left(I_{\text {in }}^{+}-I_{\text {out }}^{+}\right) \\
& V_{C 2}[\mathrm{k}+1]=V_{C 2}[\mathrm{k}]+\frac{\Delta t}{C 2}\left(-I_{\text {in }}^{-}+I_{\text {out }}^{-}\right)
\end{aligned}
$$

where $\Delta t$ is the sampling period.

\section{B. NPC converter model}

Power converter output variables are three phase currents $i_{1 a}, i_{1 b}$ and $i_{1 c}$ and phase voltages from the DC-link medium point $N$ to outputs $A, B$ and $C$. These currents and voltages can be represented by two phase vectors in a complex $\alpha-\beta$ frame. Using (3) the vectors $\overrightarrow{\boldsymbol{i}}_{\mathbf{1}}$ and $\overrightarrow{\boldsymbol{v}}_{\mathbf{1}}$ are obtained.

$$
\overrightarrow{\boldsymbol{x}}=\frac{2}{3}\left[\begin{array}{ccc}
1 & -1 / 2 & -1 / 2 \\
0 & \sqrt{3} / 2 & -\sqrt{3} / 2
\end{array}\right] \cdot\left[\begin{array}{c}
x_{a} \\
x_{b} \\
x_{c}
\end{array}\right]
$$

A total of 27 different switching combinations are available in a 3-level NPC converter, providing 19 voltage vectors at the converter output. A vector diagram of the output voltage vectors is shown in fig. 2 . Switching combinations producing redundant voltage vectors will be used for DC-link capacitor voltage balance.

\section{LCL filter model}

A per phase model of the output filter is shown in fig. 3. A state space variable model will be used with space variables being the converter side current $\vec{i}_{1}$, the grid side current $\vec{i}_{2}$ and the filter capacitor voltage $\overrightarrow{\boldsymbol{v}}_{c}$. From electric equations the

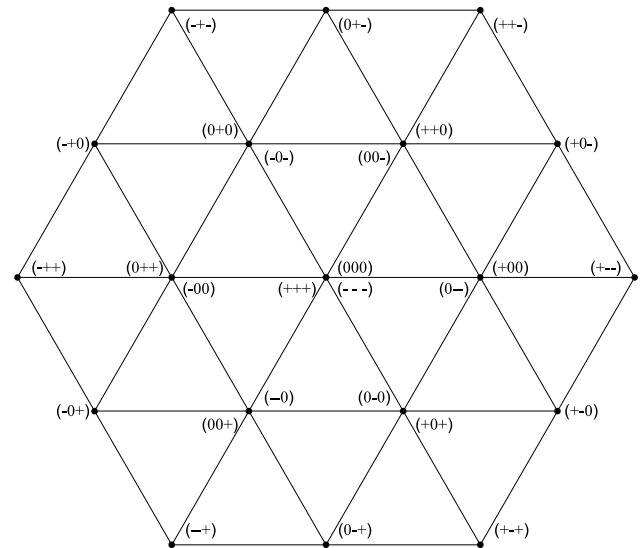

Figure 2. Voltage vectors available in a 3-level NPC converter

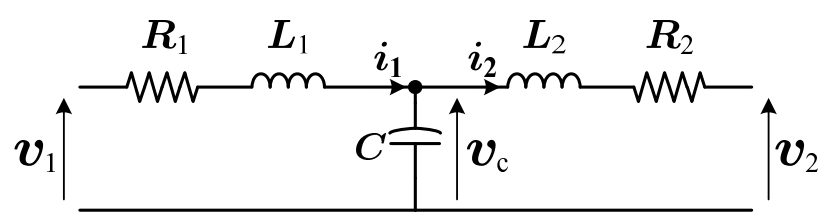

Figure 3. LCL filter per phase equivalent circuit

filter is described by the state space model (4).

$$
\begin{aligned}
{\left[\begin{array}{c}
\frac{d \overrightarrow{\boldsymbol{i}}_{\mathbf{1}}}{d t} \\
\frac{d \overrightarrow{\boldsymbol{i}}_{\mathbf{2}}}{d t} \\
\frac{d \overrightarrow{\boldsymbol{v}}_{\mathbf{c}}}{d t}
\end{array}\right]=} & {\left[\begin{array}{ccc}
-\frac{R_{1}}{L_{1}} & 0 & -\frac{1}{L_{1}} \\
0 & -\frac{R_{2}}{L_{2}} & \frac{1}{L_{2}} \\
\frac{1}{C} & -\frac{1}{C} & 0
\end{array}\right]\left[\begin{array}{c}
\overrightarrow{\boldsymbol{i}}_{\mathbf{1}} \\
\overrightarrow{\boldsymbol{i}}_{\mathbf{2}} \\
\overrightarrow{\boldsymbol{v}}_{\boldsymbol{c}}
\end{array}\right] } \\
+ & {\left[\begin{array}{cc}
\frac{1}{L_{1}} & 0 \\
0 & -\frac{1}{L_{2}}
\end{array}\right]\left[\begin{array}{c}
\overrightarrow{\boldsymbol{v}}_{\mathbf{1}} \\
\overrightarrow{\boldsymbol{v}}_{\mathbf{2}}
\end{array}\right] }
\end{aligned}
$$




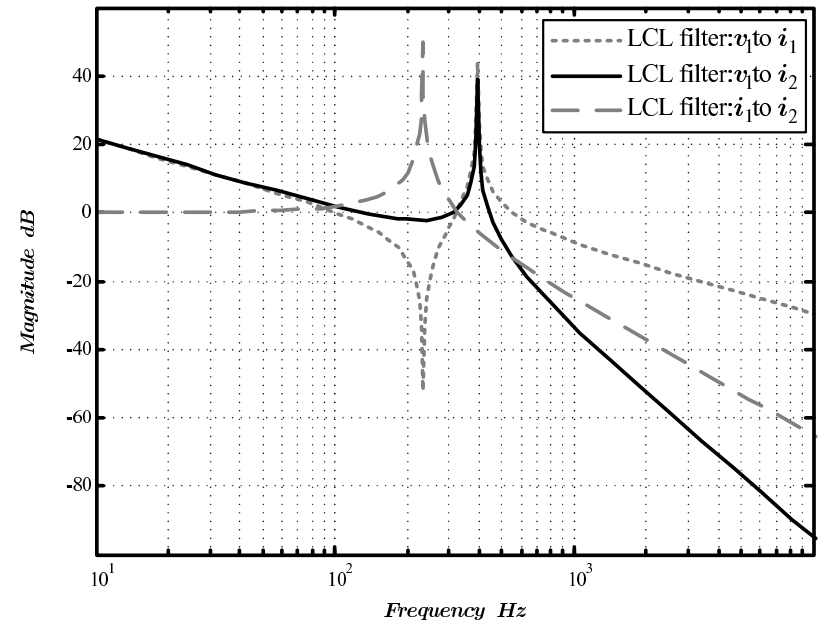

Figure 4. Filter admittance frequency response.

The system (4) has as inputs the voltage $\overrightarrow{\boldsymbol{v}}_{\mathbf{1}}$ corresponding to the voltage vector applied at the converter terminals and the grid voltage vector $\overrightarrow{\boldsymbol{v}}_{\boldsymbol{g}}$ which is considered as an external disturbance.

From the model (4) it is possible to obtain the frequency response between the input voltage $\vec{v}_{1}$ to the input and output currents $\vec{i}_{1}$ and $\vec{i}_{2}$, as well as from the input current to the output current.

A shown in fig. 4 in both frequency responses from $\vec{v}_{1}$ to $\overrightarrow{\boldsymbol{i}}_{\mathbf{1}}$ and $\overrightarrow{\boldsymbol{i}}_{\mathbf{2}}$ a resonant behavior is present. This means that any harmonic component close to the resonant frequency will be greatly amplified. The same resonant characteristic is observed between the input current $\overrightarrow{\boldsymbol{i}}_{\mathbf{1}}$ and the output current $\overrightarrow{\boldsymbol{i}}_{\mathbf{2}}$

\section{MODEL PREDICTIVE CURRENT CONTROL}

The control algorithm is based on a discrete-time equivalent model of (4). This discrete-time model is able to predict the future (time $k+1$ ) state of the system based on actual measurements (at time $k$ ) and the converter voltage to be applied. For each voltage vector available in a 3-level NPC converter, the future values of converter and grid side currents are predicted. These predicted values will be used as inputs for a cost function $G$ and the voltage vector producing the lowest value of the cost function is selected to be applied during the next sampling instant.

\section{A. DC-link capacitors voltage balancing}

According to [10] it is possible to obtain the current flowing out of the capacitors if the output currents $i_{1 a}, i_{1 b}$ and $i_{1 c}$, and the switching state of the converter are known. From the predictive model it is possible to obtain the future values of the current vector $\vec{i}_{1}$ and thus, the three phase currents. From these currents and switching state of the converter, which is different for each voltage vector available bur always known, it is possible to predict the currents flowing out of the DC-link $I_{\text {out }}^{+}$and $I_{\text {out }}^{-}$. Then, using (1) and (2) the future voltage of the DC-link capacitors is predicted.

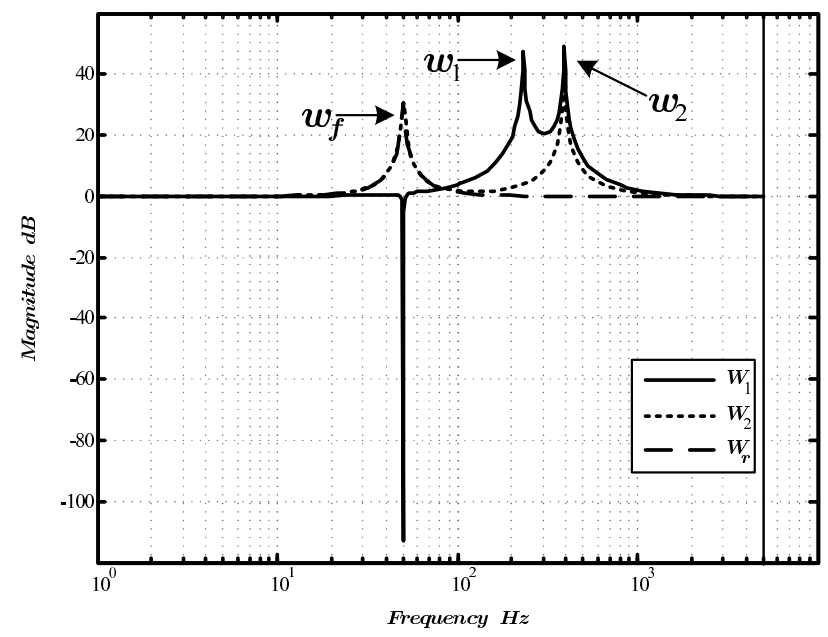

Figure 5. Frequency response of the resonance damping filters.

The cost function associated with the voltage unbalance is defined as in (5).

$$
G_{u n b}=\left(V_{C 1}[\mathrm{k}+1]-V_{C 2}[\mathrm{k}+1]\right)^{2}
$$

\section{B. Switching frequency reduction}

High power converters need to work with a reduced switching frequency in order to have lower switching losses. Because of this, a term has been added to the cost function $G$ that gives a higher costs to states producing more commutations of the power semiconductors.

The total number of commutations is counted for the last fundamental period (usually $20 \mathrm{~ms}$ ). Commutations taking place within the last fundamental period are added to the counter thus increasing the cost, while switchings that occur more than a period ago are discarded. The total number of switch commutations in the last fundamental period $N_{s w}$ is used as part of the cost function (6).

$$
G_{S W}=N_{S W}[\mathrm{k}+1]^{2}
$$

\section{Current reference tracking and filter resonance damping}

The main objective of the power converter is to be able to inject the required currents into the grid and in this way deliver a certain amount of active and reactive power. For this purpose a term on the cost function has been added that assigns a cost to the difference between the output current reference vector (in $\alpha-\beta$ coordinates) $\overrightarrow{\boldsymbol{i}}_{2}{ }^{*}$ and the predicted current vector $\overrightarrow{\boldsymbol{i}}_{2}[\mathrm{k}+1]$. The associated cost to the tracking error $G_{i_{2}}$ is given by (7)

$$
G_{i_{2}}=\left({\overrightarrow{\boldsymbol{i}_{2}}}^{*}-\overrightarrow{\boldsymbol{i}}_{\mathbf{2}}[\mathrm{k}+1]\right)^{2}
$$

As explained in section II-C, an LCL filter presents an intrinsic resonant behavior. The first resonance is produced at frequency $\omega_{1}$ and is related to parallel impedance between the filter capacitor $C$ and the grid side inductance $L_{2}$. The second resonance occurs at frequency $\omega_{2}$ due to the parallel 


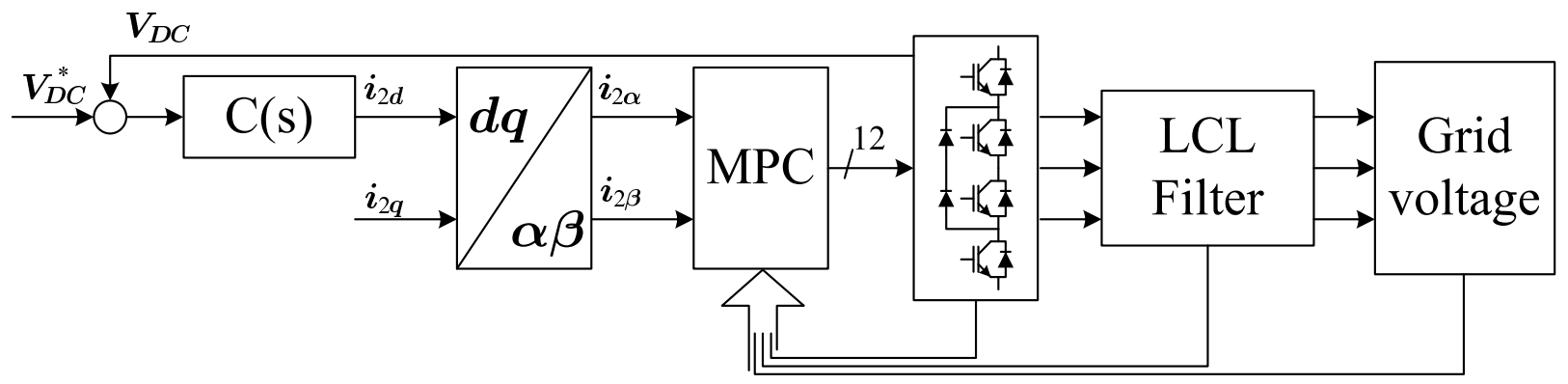

Figure 6. Control diagram.

connection of $L_{1}, C$ and $L_{2}$. The resonant frequencies are given by (8) and (9)

$$
\begin{aligned}
\omega_{1} & =\frac{1}{\sqrt{C L_{2}}} \\
\omega_{2} & =\frac{1}{\sqrt{C \frac{L_{1} L_{2}}{L_{1}+L_{2}}}}
\end{aligned}
$$

To avoid exciting the resonances it is necessary to provide a control algorithm that does not put significant energy into these two frequencies. Two achieve this it is possible to add a cost term to the cost function $G$ considering the distortion generated by the resonance in $\overrightarrow{\boldsymbol{i}}_{1}$ and to modify the cost $G_{i_{2}}$ in order to consider the energy put in frequencies close to the resonance.

Based on [11], where frequency dependant weight functions have been used to obtain a pulse-width-modulation like current spectrum; to avoid any resonance in the range of $\omega_{1}$ it is possible to add a term $G_{i_{1}}$. This term has a frequency response with high gain near the resonance frequency, thus adding a high cost if the current $\overrightarrow{\boldsymbol{i}}_{\mathbf{1}}$ has harmonic components close to the filter resonance frequency. To do this a first-order, bandpass filter tuned at $\omega_{1}$ is used to filter the predicted value of the converter side current $\vec{i}_{1}[\mathrm{k}+1]$. In this way the cost of voltages producing harmonic content nearby the resonant frequency, will be high enough to avoid their selection for the next sampling period.

On the other hand, it is necessary to include a stop-band filter in the range of the fundamental frequency, since the control strategy is supposed to put energy there, to avoid any extra cost in the reference tracking of $\overrightarrow{\boldsymbol{i}}_{2}$.

The cost functions associated to the resonance near $\omega_{1}$ is given by (10)

$$
G_{i_{1}}=W_{1}\left(i_{1_{\alpha}}^{2}+i_{1_{\beta}}^{2}\right)
$$

where $W_{1}$ is the filter shaping the frequency components of $\vec{i}_{1}$.

A similar approach is used to damp the resonance in $\omega_{2}$. A first-order pass-band filter is used in $G_{i_{2}}$ to ensure that no harmonics are present near the resonance $\omega_{2}$. The filter is centered exactly at the resonance frequency. Also a passband filter has been added to the predicted current and to the reference signal at the fundamental frequency to enhance current tracking. With all this the cost function $G_{i_{2}}$ is given by (11).

$$
G_{i_{2}}=\left(W_{2} i_{2 \alpha}[\mathrm{k}+1]-W_{r} i_{2_{\alpha}}^{*}\right)^{2}+\left(W_{2} i_{2_{\beta}}[\mathrm{k}+1]-W_{r} i_{2_{\beta}}^{*}\right)^{2}
$$

To avoid any ambiguity, i.e. low cost for signals with energy near $\omega_{2}$ for $G_{i_{1}}$ and high cost for $G_{i_{2}}$, the same digital filter used for $\overrightarrow{\boldsymbol{i}}_{2}$ is used in $W_{1}$. In this way the final filter used for $\overrightarrow{\boldsymbol{i}}_{1}$ has one peak at $\omega_{1}$ and another peak in the vicinity of $\omega_{2}$ and a very low cost at the fundamental frequency. In fig. 5 the frequency response of the digital filters $W_{1}, W_{2}$ and $W_{r}$ is shown.

Finally, the cost function to be evaluated for each of the 27 voltage vectors is given by (12).

$$
G=K_{u n b} G_{u n b}+K_{S W} G_{S W}+K_{i_{1}} G_{i_{1}}+K_{i_{2}} G_{i_{2}}
$$

Where $K_{u n b}, K_{S W}, K_{i_{1}}$ and $K_{i_{2}}$ are weight gains to change the relevance of each term within the cost function. The voltage vector producing the lowest cost is selected to be applied during the next sampling instant.

\section{ACTIVE POWER CONTROL}

DC-link voltage regulation is performed by an outer control loop. A proportional-integral (PI) controller produces an active current reference signal $i_{2 d}$ which is proportional to the output active power. Based in the transfer function (13) the control loop is designed. A low bandwidth closed loop is preferred to avoid resonances and low frequency harmonics due to voltage ripple.

$$
G(s)=\frac{3}{2} \frac{\left|V_{g}\right|}{V_{D C}} \cdot \frac{1}{\left(C_{1}+C_{2}\right) s}
$$

The active current reference and an external reactive current reference signals are rotated to the $\alpha-\beta$ plane. The resulting $i_{2 \alpha}$ and $i_{2 \beta}$ are used as references for the model predictive controller. A block diagram of the complete control system is shown in fig. 6. Where the active power controller $C(s)$ provides the active current reference signal which together with an arbitrary reactive current reference signal are rotated to $\alpha-\beta$ coordinates. The current reference vector in stationary coordinates is given to the model predictive control algorithm, represented by the MPC block. The algorithm produces the NPC converter firing pulses corresponding to the optimum voltage vector. 


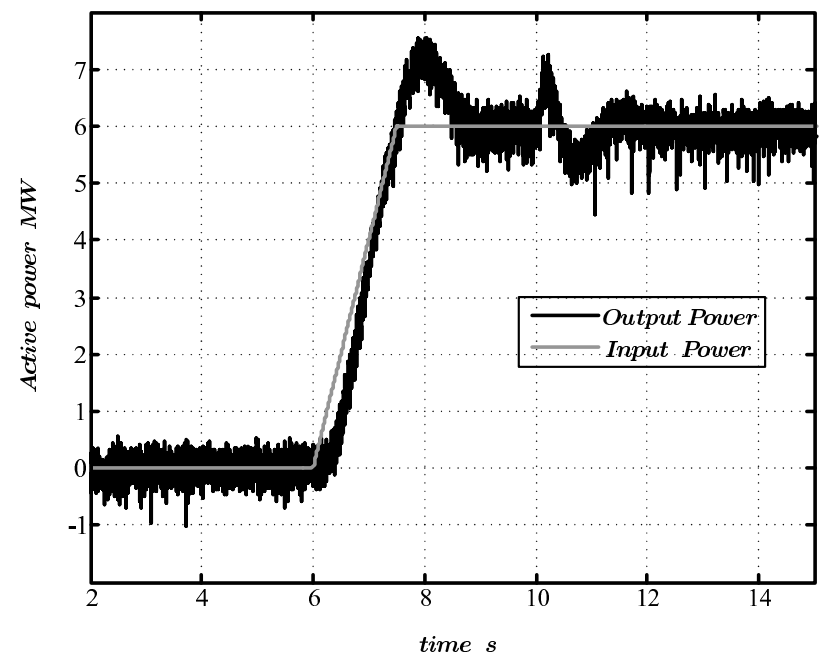

(a) Active power.

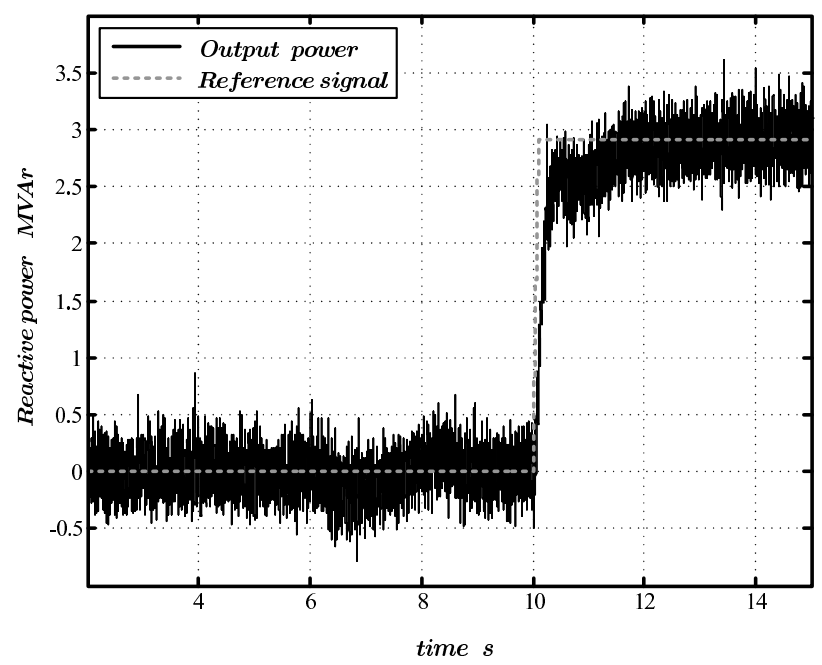

(b) Reactive power.

Figure 7. Output power regulation.

\section{Simulation Results}

Simulations were developed considering a $6 \mathrm{MW}$ 3-level NPC converter connected to a $3 \mathrm{kV}$ grid. Output filter parameters are given in table I. The gird side inductance considers a $6.11 \%$ grid impedance and and $9.77 \%$ transformer series inductance. The series impedance $2 \pi \cdot 50\left(L_{1}+L_{2}\right)$ is around $32 \%$ of the base impedance. The LCL filter has resonance frequencies in $\omega_{1}=2 \pi \cdot 181$ and $\omega_{2}=2 \pi \cdot 330[\mathrm{rad} / \mathrm{s}]$. The selected values produce resonances of 47.5 and $49.3 \mathrm{~dB}$ for $\omega_{1}$ and $\omega_{2}$, any harmonic in the resonant frequencies will be amplified by a factor of 237 and 292, respectively.

The Matlab-Simulink simulation includes a model of the three level converter, LCL filter and control algorithms. The system was tested by injecting active power into the DClink, going from 0 to rated power in $1.5 \mathrm{~s}$. The response of the control system is shown in fig. 7(a). Although the MPC controller has an intrinsic non-linear characteristic, the power response is clearly linear because it is dominated by the slow
Table I

OUTPUT FILTER PARAMETERS

\begin{tabular}{c|l|l} 
Parameter & Value & p.u. \\
\hline \hline$L_{1}$ & $481 \mu \mathrm{H}$ & 0.1119 \\
\hline$R_{1}$ & $4.95 \mathrm{~m} \Omega$ & 0.0036 \\
\hline$L_{2}$ & $884 \mu \mathrm{H}$ & 0.2057 \\
\hline$R_{2}$ & $4.22 \mathrm{~m} \Omega$ & 0.0031 \\
\hline$C$ & $528 \mu \mathrm{F}$ & 4.464 \\
\hline \hline
\end{tabular}

DC-link voltage control loop.

A reactive power distortion can be observed in fig. 7(b) during the period the active power is changing. This distortion is due to the change in the LCL filter reactive power consumption under different operating points. In time $t=10 \mathrm{~s}$, a change on reactive power demand from 0 to nominal reactive power is demanded. The change on reactive current also affects the response in active power, although it is not so relevant due to the presence of the outer active power control loop.

Filter performance is tested by comparison of converter and gride side currents. In fig. 8(a) three phase currents into the LCL filter are shown. The total harmonic distortion (THD) of the currents delivered by the NPC converter is $13.49 \%$. As shown in fig. 8(b), sinusoidal currents with almost no harmonic content are injected into the grid. The THD of grid side currents is $3.74 \%$ thus demonstrating the proper performance of the LCL filter.

Filter resonance damping is analyzed by looking at the current spectrum of both converter and grid side currents. Fig. 9(a) shows the converter side spectrum and the frequency response of the digital filter used to damp the resonance. It is clear that the control algorithm does not inject harmonics in the frequencies where the cost is high.

The same behavior is observed in the grid side current spectrum in fig. 9(b) where harmonics in the vicinity digital filter picks are avoided.

In both converter and grid side current spectrums a low frequency distortion is appreciated. This distortion is generated by the DC-link voltage control loop, which continuously changes the operation point to keep track of the voltage reference signal.

If no cost is associated with commutation losses i.e. $K_{S W}=$ 0 , the switching frequency is around $2500 \mathrm{~Hz}$ with a standard deviation of $210 \mathrm{~Hz}$. The switching frequency reduction algorithm effectively reduces the commutation losses by operating the converter with $1070 \mathrm{~Hz}$ of switching frequency with a standard deviation of $106 \mathrm{~Hz}$.

\section{CONCLUSION}

A current control algorithm for high-power grid-connected converts has been presented. On-line optimization of a cost function is performed in every sampling period allowing control of several variables and performance indexes.

The control algorithm also includes a cost on power semiconductors commutations. In this way lower switching frequency, close to $1100 \mathrm{~Hz}$, is obtained thus reducing commutation losses. Harmonic content injected into the grid because 


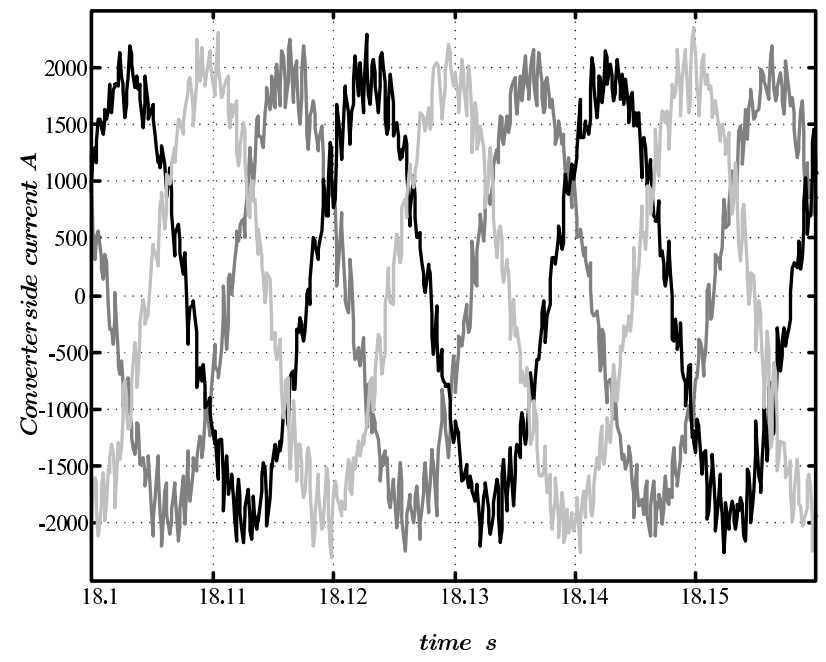

(a) Converter side current.

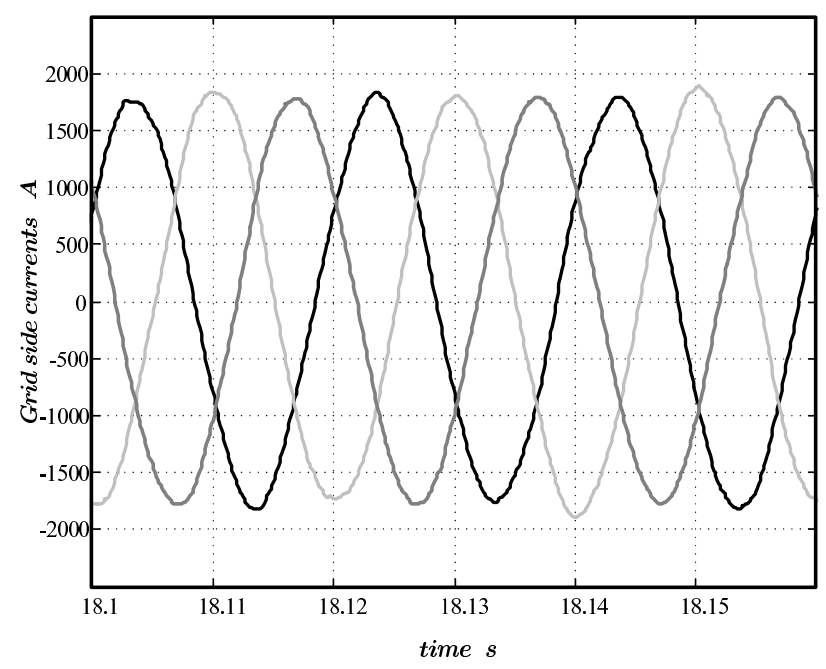

(b) Grid side current.

Figure 8 . Three phase currents.

of the low switching frequency limitations are reduced by the use of an LCL filter. Filter resonances excitation is avoided by the use of frequency dependant cost functions, so no resonant currents are injected into the grid or the filter capacitor while fundamental current is controlled to keep track of active and reactive power reference signals.

\section{REFERENCES}

[1] Makarov, Y.V. and Shuai Lu and McManus, B. and Pease, J., "The future impact of wind on bpa power system load following and regulation requirements," May 2008, pp. 1-6.

[2] M. Liserre, F. Blaabjerg, and S. Hansen, "Design and control of an lcl-filter-based three-phase active rectifier," Industry Applications, IEEE Transactions on, vol. 41, no. 5, pp. 1281-1291, Sept.-Oct. 2005.

[3] H. Karshenas and H. Saghafi, "Basic criteria in designing lcl filters for grid connected converters," vol. 3, July 2006, pp. 1996-2000.

[4] M. Borage, K.V. Nagesh, M.S. Bhatia, S. Tiwari, "Design of lcl-t resonant converter including the effect of transformer winding capacitance," Industrial Electronics, IEEE Transactions on, Accepted for future publication.

[5] K. Jalili, S. Bernet, "Design of 1cl-filters of active front end two levelvoltage source converters," Industrial Electronics, IEEE Transanctions on, Accepted for future publication.

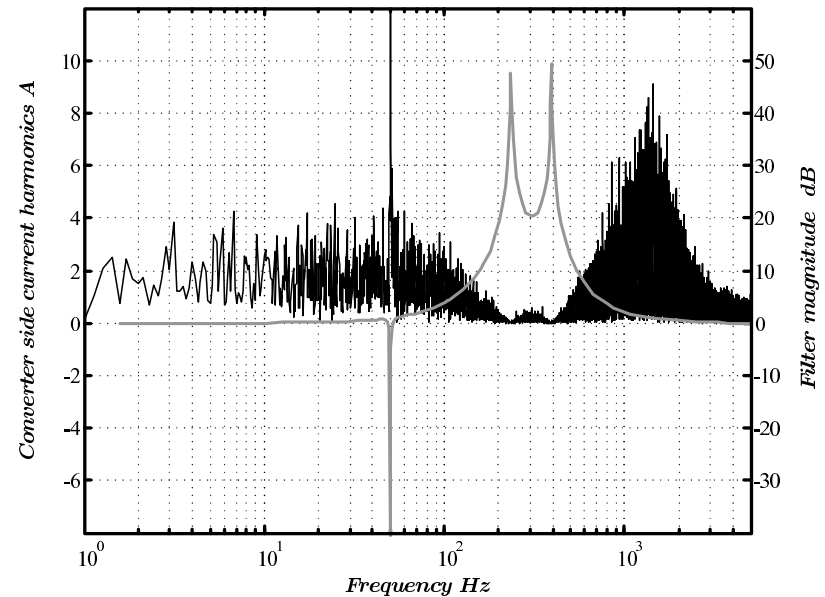

(a) Converter side current spectrum

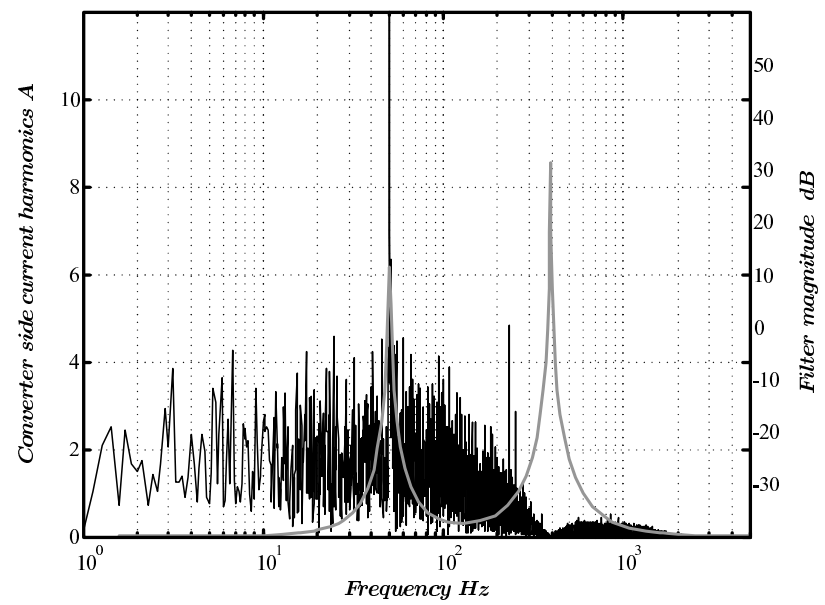

(b) Grid side current spectrum.

Figure 9. Current spectrum.

[6] A. Papavasiliou, S. Papathanassiou, S. Manias, and G. Demetriadis, "Current control of a voltage source inverter connected to the grid via lcl filter," June 2007, pp. 2379-2384.

[7] S. Mariethoz and M. Morari, "Explicit model-predictive control of a pwm inverter with an lcl filter," Industrial Electronics, IEEE Transactions on, vol. 56, no. 2, pp. 389-399, Feb. 2009.

[8] P. Cortes, M. Kazmierkowski, R. Kennel, D. Quevedo, and J. Rodriguez, "Predictive control in power electronics and drives," Industrial Electronics, IEEE Transactions on, vol. 55, no. 12, pp. 4312-4324, Dec. 2008.

[9] J. Rodriguez, J. Pontt, C. A. Silva, P. Correa, P. Lezana, P. Cortes, and U. Ammann, "Predictive current control of a voltage source inverter," Industrial Electronics, IEEE Transactions on, vol. 54, no. 1, pp. 495503, Feb. 2007.

[10] N. Celanovic, D. Boroyevich, "A comprehensive study of neutral-point voltage balancing problem in three-level neutral-point-clamped voltage source pwm inverters," IEEE Trans. on Power Electron., vol. 15, no. 2, pp. 242-249, March 2000.

[11] P. Cortes, J. Rodriguez, D. Quevedo, and C. Silva, "Predictive current control strategy with imposed load current spectrum," Power Electronics, IEEE Transactions on, vol. 23, no. 2, pp. 612-618, March 2008. 